\title{
Survey Data in Teaching Project (SDiT)
}

\section{Enhancing critical thinking and data numeracy}

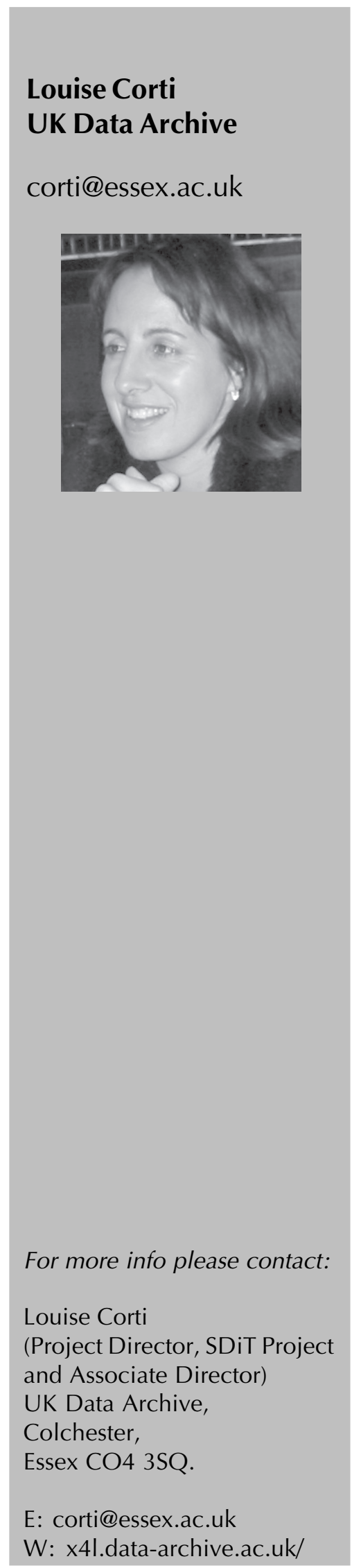

\section{Background: Under-use of data in the classroom}

Through a number of strategic investments by both the JISC and the ESRC, the UK academic community has access to a unique and expansive range of digital data resources. The Economic and Social Data Service (ESDS) [3], of which the UK Data Archive [7] is a service provider, is a national data service that provides access and support for an extensive range of key economic and social data, both quantitative and qualitative, spanning many disciplines and themes. It comprises a number of specialist data services that promote and encourage data usage in teaching and research. However, while individual datasets are used extensively in academic research they are significantly under-used in learning and teaching programmes within Higher Education, at both undergraduate and postgraduate level, and rarely used in Further Education.

Previous investigations into levels of data literacy in the UK reveal that the UK is lacking significantly in a stock of individuals with good quantitative data analysis skills. The JISC 5/99 Programme Task Force on The Use of Numeric Data in the Classroom project, centred around how quantitative data is currently used in the classroom, offered valuable insights and evidence into the benefits and barriers surrounding the adoption of data handling in social science teaching practise [6]. The survey looked at when and how data were used in the classroom, thereby providing a recent overview of the pedagogical issues that underlie the rationale for the Survey Data in Teaching (SDiT) project [8]. The few HE lecturers using data in their teaching used them either to add an empirical dimension to the subject, to teach statistics or data analysis methods, or to teach numeracy or critical thinking skills. Certainly, the main focus is on using data to teach research methods, with very few using 'live' social data to illustrate substance.

For teachers, the barriers to using data cited are largely to do with lack of awareness of data sources, the lack of time available to prepare data and build its use into courses, and finally the lack of access to suitable data both physically and conceptually.

\section{Aims of the SDiT project}

The SDiT project aimed to consider how repurposing existing data resources housed at the UK Data Archive (UKDA) for teaching and learning might increase their use, while recognizing that there is considerable scope for increasing use of specially tailored teaching datasets and associated online learning materials within the FE sector.

The SDiT project was funded under the Exchange for Learning (X4L) Programme [4], which has been motivated by the drive to make the most of the considerable investment that has taken place in a range of JISC resources for teaching and learning. The Programme is exploring a range of strategies, methods, tools and metadata standards that will enable the repurposing of elearning materials. Pedagogical outcomes are at the heart of the Programme, with a focus on learning activities and outcomes, as is the challenge to elucidate strategies that will encourage sustainability and widespread adoption of e-learning materials. 
Simplifying and re-purposing complex data, for example, the larger government survey datasets held by the UKDA, is one way of opening up their accessibility. A grander mission of the SDiT project was to work towards improving the data literacy of GCE ' $A$ ' level and university students to:

- enable a better understanding of the use of social science data as applied to real-life problems

- enhance skills in manipulating numerical data textbooks, newspapers, reports and databases

- conceptualise the characteristics of quantitative data so that they can be used to support substantive arguments

- become critical consumers of these data.

Thus the focus of the content of the SDiT resources was to integrate the mechanics of data analysis with theoretical material. Data are never isolated from theory, and it is never the case that data 'speak for themselves'. The empirical orientations were thus: research methods in social science; potential of survey data to answer questions; survey measurement; sampling; basic data management/basic data analysis and resource discovery skills. Other related initiatives in this area include the CHCC project (HE level) [2] and the more fundamental CensusAtSchool (school level) projects [1].

Re-purposing in the case of this project meant repackaging complex data with educational narratives and exercises into discrete 'chunks'. Ready-made learning objects or modules can be tried and tested by tutors and incorporated into their teaching in a flexible way. The project's deliverables included: the creation of new and easily accessible datasets; accompanying light-weight substantive learning materials; an intuitive and flexible means of delivering these materials; high quality and standardised descriptions of the resources; and an evaluation and awareness raising strategy.

As a national JISC Service provider the UKDA is in a strong position to offer its resources to the learning and teaching communities for developing more tailored resources. In turn it needs the advice and input from instructors in the classroom on how to develop the pedagogic aspects of learning resources: how to repurpose and apply the content; where to position the resources in the learning process; and advice on the usability and functionality of the resources.

The small scale project, running over eighteen months with a team of four part-time staff, developed, piloted and evaluated a set of survey data-based resources, and documented the experiences, processes and outcomes of the project itself.

\section{The teaching and learning resources created}

X4L SDiT uses the study of crime in society to show how existing data sources can be utilised to answer questions about crime. Crime is a popular topic taught across the curriculum and is relevant to a range of social science disciplines, such as sociology, politics, management and general studies and psychology, as well as areas such as public service GNVQ, media and citizenship studies. The resources are appropriate for ' $A$ ' level syllabi but are also highly applicable for undergraduate and postgraduate learning. The outputs created are a variety of free teaching and learning resources relating to social science and statistics, based on learning strategies that encourage the teaching of research methods within a substantive context.

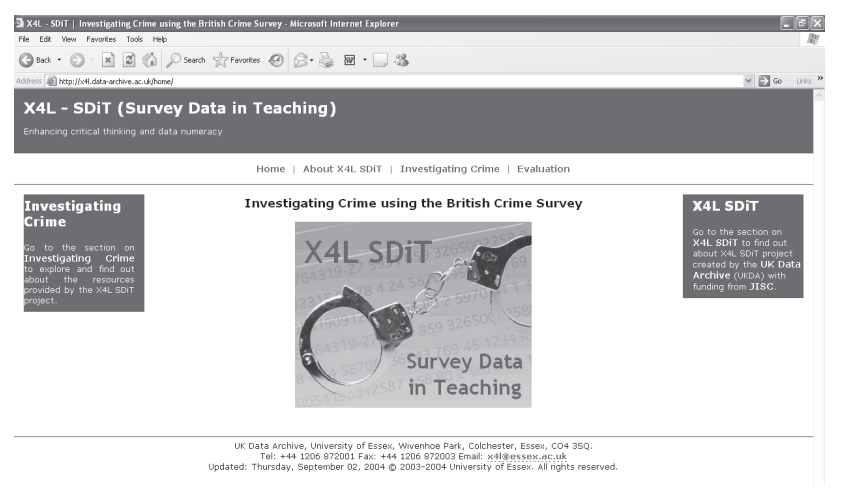

Three types of resources were developed: four learning modules on the use of crime data; two appendices on sampling and statistical inference; a glossary of statistical terms and two resource discovery guides, one on the use of the Nesstar online data exploration system [5], and another on how to find data and documentation (resource discovery) in the UK Data Archive.

The module topics are as follows:

- Module 1: Tracking Crime: Police Recorded Crime Figures, Trends and Reasons for Change

- Module 2: Theories about Crime: Public Perceptions of Crime Rates

- Module 2 Appendix: Crime and Political Parties, aimed at politics students

- Module 3: Gathering Evidence: How to Investigate Crime Statistics

- Module 4: Examining Evidence: How to Interrogate Crime Statistics

- Module 4 Appendix: Reliability of Results

- Module 5: Resource Discovery - Searching for Evidence: Sources of Crime Data

- Module 6: Guide to using Nesstar 


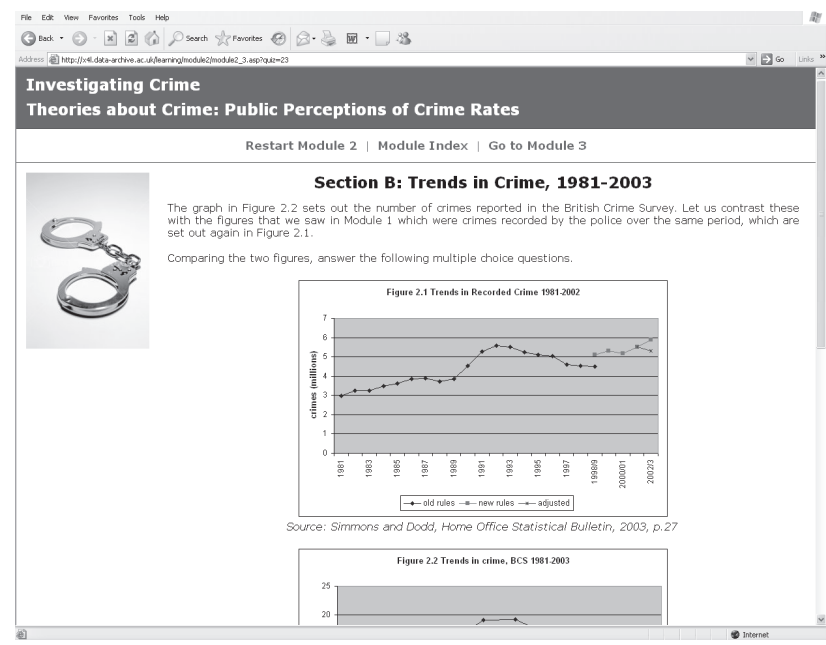

Modules were designed to be used as part of standard classroom teaching or as additional/self-paced learning activities and were created in a number of formats to suit different pedagogical needs:

- On-line, interactive self-paced modules hosted (long term) at the UK Data Archive web site

- Printable and reproducible hard copies:

- bound paper workbook with accompanying CDROM

- Microsoft Word files

- Adobe PDF files

- Microsoft PowerPoint presentations which can be used to provide slides or handouts

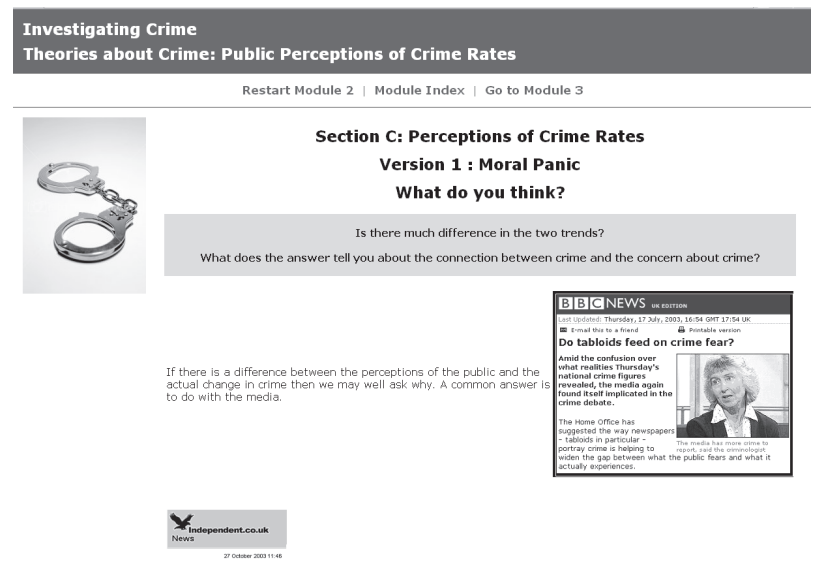

The project also created freely available new teaching datasets and access to data exploration software, for which a guide to accessing them for the data handling exercises is also provided.

- A teaching version of the British Crime Survey dataset available in multiple formats (SPSS, STATA, NSDStat and tab delimited (suitable for
MS Excel) and available from three systems:

- via the freely available online browsing system, Nesstar;

- via the UKDA download/ordering system;

- via the X4L project website or SDiT CD-Rom.

- Free demonstration version of very simple and user-friendly data analysis software, which is utilised in the last two of the teaching modules was created, NSDStat.

For promotional purposes, the resources listed above comprising the modules, guides, data and data analysis software, have been printed and bound as an SDiT Resources Pack, with an accompanying CD-ROM.

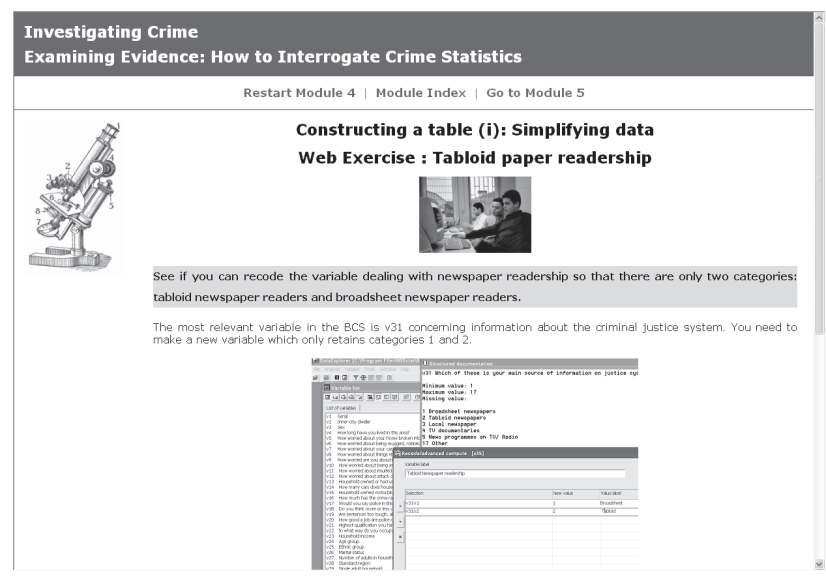

A Tutor Guide to accompany the resources has also been prepared which is divided into three sections:

- Section A: Teaching and Learning Resources

- Introduction to the teaching and learning resources: Investigating Crime

- Overview of the teaching and learning resources available for the use of tutors and students, including instructions for accessing the on-line files and downloading of software;

- Synopsis of learning modules - subject areas covered, and examples of use including model answers and suggestions for classroom exercises;

- Section B: Using the Survey Data in Teaching (SDiT) Materials

- Using data resources in your teaching, providing an exemplar/model of how such resources could be applied to other topics e.g. health, race etc.

- Model answers - Module 1

- Key Skills mapping, a mapping of the resources to Key Skills levels 3 and 4, that is, appropriate to 'A' level

- SPSS syntax for data analysis exercises 
- Section C: Evaluations

- Case studies of using the SDiT resources, based on feedback and usage of the resources in the classroom by tutors and students;

\section{Experiences of re-purposing}

The modules for HE and FE were authored and piloted primarily by lecturers who are, or have been, responsible for teaching quantitative skills in social science (in political science and sociology). From the start, the project considered it critical that the pedagogical concerns drive the content of the resources which should then be 'translated' to the teams building and implementing the resources (extracting teaching datasets; writing NESSTAR user guides; designing and building the web interface (and CD-ROM) for the resources; undertaking evaluation activities and designing promotional materials), based at the UK Data Archive. The experience of working very closely in partnership with tutors also helped at the evaluation stage when rich feedback could be obtained from them trialling the resources in their own teaching. Moreover, the pedagogical aspects of the resource creation and implementation could be documented in the tutor guide and in final reports. The greatest lesson learned from the project was that drafting such resources takes up huge resources (time for coordinating, authoring, evaluating, rewriting, mounting on web and so on), particularly if they are to be relevant, appealing, flexible, lightweight, 'discrete' rather than courseware, and suitable for web-based delivery.

The HE and FE staff and students, and information professionals who helped advise on and evaluate the project, considered the learning materials and associated guides created by the project to be impressive and highly useful. Moreover, they felt that the project had delivered a neat and flexible model that both answered the data literacy challenge in hand and demonstrated the concept of repurposing. Pre-prepared materials can save teachers considerable time and effort, and also offer ideas of how to utilise data sources in their own teaching. The mapping of modules and resources to syllabi and Key Skills (levels 3 and 4) was attractive to FE tutors. In this way it would be easier to quickly identify appropriate materials from learning banks or repositories (such as the JORUM) for use in their own teaching. Case studies from the teacher and student evaluations have been written up and are published in the SDiT Tutor Guide.
Finally, it is clear from this small scale project, a toedipping exercise, that embedding strategies are required to get JISC resources used on a widespread and takenfor-granted basis. There is a need to reach out to teachers on the ground, in addition to Information and Learning Technology staff, within educational institutions. This requires promotion and encouragement from organisations and policy makers in fields of education and Information and Learning Technologies (ILT), like JISC, BECTA, LSC and the DfES, to help utilise JISC resources and Programme outputs like the $X 4 \mathrm{~L}$, and to help join up the many disparate e-learning initiatives. Furthermore, partnership and collaboration of JISC Service Providers, like ESDS, with teachers to undertake focused projects based on data resources with specific outcomes (e.g. by topic area matched to syllabus) would be beneficial. Our desire would be to see the use of such resources help build up data literacy and data handling skills amongst students, from school age and upwards.

\section{References}

[1] CensusAtSchool (2003), Nottingham Trent University www.censusatschool.ntu.ac.uk/

[2] Collection of Historical and Contemporary Census Data and Related Materials (CHCC) (2003) Universities of Manchester, Leeds, Glasgow and Essex Sept 2003 www.chcc.ac.uk

[3] Economic and Social Data Service (ESDS) web site www.esds.ac.uk/

[4] JISC Exchange for Learning (X4L) Programme $w w w . j i s c . a c . u k /$ index.cfm?name=programme_x4l

[5] NESSTAR: nesstar.esds.ac.uk/webview/ The UKDA's online survey data browsing and download system

[6] Rice et al (2001), Report on Use of Data In Teaching and Learning, Edinburgh University datalib.ed.ac.uk/projects/datateach.html

[7] UK Data Archive (UKDA) www.data-archive.ac.uk

[8] SDiT Website x4l.data-archive.ac.uk/ 